\title{
ESTRATÉGIAS DE GESTÃO SUSTENTÁVEL E DESEMPENHO EXPORTADOR EM UMA EMPRESA DA TERCEIRA GERAÇÃO DA CADEIA PETROQUÍMICA
}

\author{
Paulo Fernando Marschner ${ }^{1}$, Fernando Antonio Egert ${ }^{2}$, Lucas Veiga Avila ${ }^{3}$, Analisa Tiburski Sommer ${ }^{4}$ \\ ${ }^{1}$ paulofernandomarschnerehotmail. com \\ 2egertehotmail.com \\ 3adlucasveiga@gmail.com \\ ${ }^{4}$ analisa-somer@uergs.edu.br
}

\section{Resumo}

A presente pesquisa possui como objetivo identificar as estratégias de gestão sustentável e o desempenho exportador de uma empresa de transformados plásticos. A transformação de material plástico é a terceira geração da cadeia produtiva petroquímica e é responsável por produzir embalagens, peças e utensílios para quase todos os segmentos produtivos da economia. Em termos metodológicos desenvolveu-se uma pesquisa qualitativa de abordagem descritiva. A coleta e análise dos dados referentes às estratégias de gestão sustentável ampararam-se nos modelos de Placet, Anderson, Fowler (2005) e de Lacy et al (2010). Já o desempenho exportador foi analisado a partir dos estudos de Papadopoulos e Martín (2010). Os principais resultados revelaram que a sustentabilidade está totalmente integrada a estratégia da empresa, contudo apresenta um desempenho exportador ainda incipiente.

Palavras-chave: Estratégias sustentáveis. Desempenho exportador. Transformados plásticos.

\section{SUSTAINABLE MANAGEMENT AND EXPORT PERFORMANCE STRATEGIES IN A THIRD GENERATION OF THE PETROCHEMICAL CHAIN}

\begin{abstract}
The present research aims to identify the strategies of sustainable management and the export performance of a company of plastic transformers. The transformation of plastic material is the third generation of the petrochemical production chain and is responsible for producing packaging, parts and utensils for almost all productive segments of the economy. In methodological terms a qualitative research of descriptive approach was developed. The collection and analysis of data on sustainable management strategies were based on the models of Placet, Anderson, Fowler (2005) and Lacy et al (2010). The export performance was analyzed from the studies of Papadopoulos and Martin (2010). The main results revealed that sustainability is fully integrated with the company's strategy, yet it has a still incipient export performance.
\end{abstract}

Keywords: Sustainable Strategies. Performance Exporter. Transformed Plastics.

\section{Introdução}

Com o propósito de buscar uma gestão que incorpore a sustentabilidade à sua estratégia e ao seu modelo econômico, as organizações precisam trabalhar os aspectos sociais, ambientais e econômicos em conjunto, a fim alinhar as suas estratégias empresariais com esse desafio emergente (ALIEVI; ANTINARELLI, 2015). Pasqualotto e Ugalde (2010) destacam que as exigências de uma postura responsável por parte das organizações em relação à sustentabilidade 
são cada vez mais recorrentes no ambiente empresarial, e intensificam-se ainda mais no que tange à adaptação dos produtos para fins de internacionalização.

De acordo com Wright e Giovinazzo (2004) as empresas que atuam na indústria de plásticos têm um enorme desafio de assegurar a sustentabilidade deste setor, cujos produtos, quando descartados podem levar em alguns casos até três séculos para se degradar. Para os autores, a preocupação com a sustentabilidade é um fator levado em consideração pelos consumidores e stakeholders envolvidos nas mais determinadas áreas do negócio, levando assim a sustentabilidade em conta para suas decisões de compra.

A indústria de transformação de plásticos é de grande importância para o Brasil, onde se destaca como principal produtor da América Latina, e consequentemente produz e descarta grandes quantidades de produto. Nesse sentido, Wright e Giovinazzo (2004) argumentam que a indústria de plásticos deve perguntar-se quais ações estratégicas que devem tomar, a fim de garantir o desenvolvimento sustentável. Essa perspectiva torna-se relevante na medida em que os consumidores de outros países, sobretudo os desenvolvidos estão cada vez mais conscientes dos aspectos ambientais que permeiam os produtos que compram (MASCARENHAS; COSTA 2011). Viola (2003) explica que esse contexto configura um cenário de fragilidade para os países exportadores, em especial aos países em desenvolvimento como o Brasil e os demais latino-americanos, já que nestes existe dificuldade de compreensão da importância da sustentabilidade.

Diante desse contexto, este trabalho possui como objetivo identificar as estratégias de gestão sustentável e o desempenho exportador de uma empresa da terceira geração da cadeia petroquímica. Para atender o objetivo proposto desenvolveu-se uma pesquisa de cunho qualitativo e descritivo em uma empresa que comercializa produtos a partir da transformação de fibras de vidro (fiberglass) e do polietileno. Nesta cadeia produtiva em que a responsabilidade pela produção e seus resíduos é tão emergente, a adoção da sustentabilidade aos seus processos e produtos pode impulsionar sua participação no mercado internacional através da exportação.

Este artigo está estruturado em seis seções com os seguintes tópicos: introdução; fundamentação teórica; características da indústria de materiais plásticos; método de estudo; análise e apresentação dos resultados; e considerações finais.

\section{Fundamentação teórica}

Esta seção apresenta as definições acerca das estratégias de gestão sustentável, bem como o desempenho exportador, adotada pelos autores com base nas definições identificadas na literatura.

\subsection{Estratégias de gestão sustentável}

A sustentabilidade empresarial tem se consolidado como uma alternativa de gerenciar atividades de forma sustentável e atender às expectativas dos interessados, sejam acionistas, colaboradores ou mesmo à sociedade (FIALHO, 2006; 2008). Ou seja, é a capacidade da empresa em criar valores sustentáveis e inclui ainda uma relação satisfatória com seus stakeholders (CIASULLO; TROISI, 2013). Elkington (1997) questiona o resultado financeiro como o mais importante para as organizações. De acordo com o autor é importante mensurar o retorno ambiental e social juntamente com a contabilidade, para somente assim determinar o resultado final. Cardoso (2012) corrobora com tal perspectiva ao enfatizar que tais fatores sempre afetaram as empresas, contudo há pouco tempo estão sendo reconhecidos por estas e pelo mercado, já que ambos são afetados por impactos não financeiros nas suas operações. 
Neste sentido, Placet, Anderson e Fowler (2005) indicam que o desenvolvimento sustentável no contexto das organizações e seus stakeholders possuem três objetivos estratégicos: a gestão ambiental, a responsabilidade social e a prosperidade econômica. A gestão ambiental refere-se à gestão dos recursos naturais como o ar, água, terra e ao ecossistema em que a organização está inserida. A responsabilidade social corresponde à qualidade de vida dos colaboradores das organizações e a sociedade como um todo. E a prosperidade econômica representa o resultado do desenvolvimento de oportunidades para a empresa e para a comunidade onde ela está inserida (PLACET; ANDERSON; FOWLER, 2005).

$\mathrm{O}$ desenvolvimento de estratégias que atendam as demandas por produtos e serviços sustentáveis é um dos principais desafios para as organizações e seu corpo administrativo. Tais estratégias implicam em novos métodos de gestão, por isso as empresas terão que incorporar em seus objetivos a busca por novos modelos, que além de criarem de valor para a sociedade e colaboradores, devem fomentar uma cultura organizacional voltada para metas de sustentabilidade (LACY et al, 2010). Para tal, as empresas devem investir permanentemente na qualidade e aperfeiçoamento de suas relações com a sociedade procurando por formas de gestão que combine os interesses da sociedade com os interesses da organização. Buscando assim, legitimidade, crescimento e sustentabilidade (AGLIERI; AGLIERI; KRUGLIANSKAS, 2009).

Sendo assim, é importante enfatizar que a adoção de tais práticas pode trazer vantagens sobre as empresas reativas que apenas cumprem as suas obrigações (GONZÁLES-BENITO; GONZÁLES-BENITO, 2006, 2005). A adoção de práticas ambientais que vão além do cumprimento das normas legais tendem a gerar vantagens competitivas, bem como a redução de custos, melhoria na qualidade e geração de novos produtos e processos (BANSAL; ROTH, 2000; YANG et al, 2010). Todavia, a implementação da sustentabilidade como estratégia é um desafio, já que para muitas organizações a estratégia é uma ferramenta utilizada apenas para redução de custos e expansão dos negócios, enquanto a proteção ambiental é vista como uma prática desnecessária e cara (PLACET; ANDERSON; FOWLER, 2005)

\subsection{Desempenho exportador}

A política de liberação comercial adotada pelo Brasil nos anos de 1990 possibilitou aos consumidores brasileiros a opção de adquirir produtos importados com qualidade superior e a um preço mais acessível. Este cenário fez com que as empresas nacionais reagissem buscando consumidores internacionais e reduzindo sua dependência exclusiva do mercado doméstico (KLOTZLE; THOMÉ, 2006). No Brasil assim como nos demais países em desenvolvimento grande parte das empresas não possui investimentos em instalações comerciais ou fabris em outros países. Sendo assim, a comercialização de produtos tende a ser a principal forma de entrada e também a que envolve um menor risco na internacionalização (JOHANSON; WIEDERSHEIM-PAUL, 1975; JOHANSON; VAHLNE, 1990).

O processo de internacionalização tem sido amplamente discutido sob o ponto de vista teórico e alicerça-se em duas principais vertentes, um denominada comportamentalista, e outra denominada teoria eclética de internacionalização (ARBIX, SALERMO; DE NEGRI, 2005). A primeira vertente possui a premissa de que a internacionalização ocorre gradualmente e de forma sequencial, incluindo práticas como a associação com outras empresas ou licenciamento de produtos, por exemplo. Parte considerável desta literatura é decorrente do trabalho de Johanson e Vahlne (1977). A segunda vertente é decorrente do trabalho de Dunning (1993) e presume que a racionalidade limitada dos agentes econômicos e o comportamento oportunista são maiores no mercado internacional do que no mercado doméstico. Dessa forma, é esperado que uma empresa para se tornar uma multinacional necessita inicialmente ser líder em seu país de origem, acumular ativos tangíveis e intangíveis com elevados custos de transação no mercado internacional (ARBIX; SALERNO; DE NEGRI, 2005). 
Tendo em vista que o sucesso nas exportações de firmas industriais de países em desenvolvimento como o Brasil está diretamente atrelado aos investimentos prévios no mercado exterior (HIDALGO; DA MATA, 2009), a avaliação do desempenho exportador pode fornecer indícios acerca da atuação empresarial em mercados externos. Para tal, Papadopoulos e Martín (2010) sugerem que a avaliação do desempenho exportador deve considerar duas dimensões: uma econômica (indicadores de desempenho financeiros), e uma dimensão estratégica (medidas pelas quais os objetivos da empresa são alcançados). A pesquisa de Papadopoulos e Martín (2010) indica três considerações essenciais sobre o desempenho exportador: i) pode ser definido como uma construção de duas dimensões: uma econômica e outra estratégica; ii) a dimensão econômica contribui de forma mais significativa do que a estratégica; e iii) a conceituação da dimensão econômica é formativa. Para os autores as vendas no mercado internacional e a rentabilidade não são necessariamente correlacionadas. A medida inclui tanto as facetas de desempenho econômico, isto é, a eficácia (vendas) e a eficiência (rentabilidade), e mostra uma contribuição significativa e muito semelhante de ambos os indicadores para a formação de desempenho econômico.

\section{Indústria de transformação de material plástico}

A indústria de transformados plásticos se encontra dentro da cadeia produtiva petroquímica, que é dividida em três gerações. Na primeira, estão as produtoras dos petroquímicos básicos, resultantes da primeira transformação de correntes petrolíferas por processos químicos. Na segunda, estão as produtoras de resinas termoplásticas (polietilenos e polipropilenos) e de intermediários, cujos produtos resultantes do processamento são o acetato de vinila, óxido de propeno, etc. Esses intermediários são transformados em produtos finais petroquímicos, como PVC, poliestireno, resinas termoestáveis, polímeros para fibras sintéticas, elastômeros, poliuretanas, bases para detergentes sintéticos, tintas, etc. (GOMES; DVORSAK; HEIL, 2005).

$\mathrm{Na}$ terceira geração do complexo petroquímico, estão as indústrias de transformados plásticos que tem como matérias-primas básicas as diferentes resinas termoplásticas da indústria de poliéster (SEBRAE, 2008). A indústria de material plástico produz embalagens, peças e utensílios para quase todos os segmentos produtivos da economia. As características de flexibilidade, resistência (química, física e térmica), densidade, peso, transparência, brilho e impermeabilidade de cada produto plástico decorrem da utilização de diferentes insumos de poliéster o que permite o desenvolvimento de uma grande variedade de produtos. A comercialização e a distribuição, tanto no atacado quanto no varejo, complementam a cadeia principal, estabelecendo uma relação com o mercado (SEBRAE, 2008).

Atualmente, o maior produtor e transformador de plásticos é a China com uma produção de aproximadamente $25 \%$ do total mundial, seguido pelo grupo europeu representando $20 \%$, e na sequência pelo Tratado-Norte Americano de Livre Comércio (Canadá, México e Estados Unidos) que produz $19,4 \%$. O Brasil representa $2,4 \%$ de toda a produção mundial de transformados plásticos, como segue no Quadro 1.

Quadro 1 - Principais produtores de transformados plásticos

\begin{tabular}{|l|c|}
\hline \multicolumn{1}{|c|}{ Países/territórios } & $\mathbf{1 0 0 \%}$ \\
\hline China & $24,8 \%$ \\
\hline Europa (EU + CH + NO) & $20 \%$ \\
\hline NAFTA & $19,4 \%$ \\
\hline Representante da Ásia & $16,4 \%$ \\
\hline Oriente Médio, África & $7,3 \%$ \\
\hline
\end{tabular}




\begin{tabular}{|l|l|}
\hline Japão & $4,4 \%$ \\
\hline CIS & $2,9 \%$ \\
\hline Brasil & $2,7 \%$ \\
\hline América Latina (exceto Brasil) & $2,1 \%$ \\
\hline
\end{tabular}

Fonte: ABIPLAST (2014)

Grande parte das empresas brasileiras que atuam no setor de transformados plásticos é pequena, ou micro empresa. As de médio porte representam $6 \%$, ao passo que as grandes empresas representam apenas $0,5 \%$ do total, como segue no Quadro 2.

Quadro 2 - Tamanho das empresas brasileiras de transformados plásticos

Fonte: ABIPLAST (2014)

\begin{tabular}{|l|c|c|}
\hline \multicolumn{1}{|c|}{ Tamanho } & Quantidade & \% \\
\hline Grandes & 62 & $0,5 \%$ \\
\hline Médias & 696 & $6 \%$ \\
\hline Pequenas & 2739 & $23,60 \%$ \\
\hline Micro & 8093 & $69,80 \%$ \\
\hline
\end{tabular}

Segundo dados do Sindicato das Indústrias de Material Plástico do Estado do Rio Grande do Sul, o estado congrega mais de 800 indústrias do setor entre filiadas e associadas, o que representa aproximadamente 7\% das empresas do Brasil. No Quadro 3 é possível observar os principais destinos da exportação dos transformados plásticos.

Quadro 3 - Destinos dos transformados plásticos

\begin{tabular}{|l|c|c|c|c|}
\hline \multicolumn{1}{|c|}{$\mathbf{2 0 1 4}$} & US\$ MIL & \% US\$ & TON & \% PESO \\
\hline Países & $1.346,21$ & $100 \%$ & 235.937 & $100 \%$ \\
\hline Argentina & 261.040 & $19,4 \%$ & 49.136 & $20,8 \%$ \\
\hline Países Baixos (Holanda) & 213.052 & $15,8 \%$ & 18.811 & $8,0 \%$ \\
\hline Estados Unidos & 126.414 & $9,4 \%$ & 25.697 & $10,9 \%$ \\
\hline Paraguai & 98.335 & $7,3 \%$ & 23.126 & $9,8 \%$ \\
\hline Chile & 90.725 & $6,7 \%$ & 15.428 & $6,5 \%$ \\
\hline Colômbia & 56.442 & $4,2 \%$ & 8.062 & $3,4 \%$ \\
\hline Uruguai & 52.555 & $3,9 \%$ & 13.922 & $5,9 \%$ \\
\hline México & 47.978 & $3,6 \%$ & 7.868 & $3,3 \%$ \\
\hline Venezuela & 44.669 & $3,3 \%$ & 5.448 & $2,3 \%$ \\
\hline Bolívia & 35.963 & $2,7 \%$ & 7.624 & $3,2 \%$ \\
\hline Peru & 27.939 & $2,1 \%$ & 4.687 & $2,0 \%$ \\
\hline Alemanha & 19.784 & $1,5 \%$ & 3.476 & $1,5 \%$ \\
\hline Suíça & 16.492 & $1,2 \%$ & 3.160 & $1,3 \%$ \\
\hline Outros & 254.824 & $18,9 \%$ & 49.491 & $21,0 \%$ \\
\hline
\end{tabular}

Fonte: ABIPLAST (2014)

A Argentina é a principal importadora dos transformados plásticos, pois é a maior importadora do Brasil representando um saldo de US\$261.040, equivalente à 20,8\% de todas as toneladas. Os Países Baixos (Holanda) ocupam a segunda posição, representam também o principal destino de todo o continente europeu, o saldo comercial em 2014 foi de US\$ 213.052, em seguida os Estado Unidos, Paraguai e Chile. 


\section{Método de estudo}

Para anteder ao objetivo proposto, desenvolveu-se uma pesquisa de abordagem qualitativa e natureza descritiva. Para Merriam (1998) os métodos qualitativos são os mais indicados para pesquisas interpretativas ou críticas porque ocupam lugar de reconhecimento por estabelecer a possibilidade de se estudar os fenômenos humanos e suas intricadas relações sociais nos mais diversos ambientes. Envolve um grande número de técnicas e procedimentos interpretativos que procuram descrever, decodificar o sentido e não a frequência de eventos ou fenômenos.

\subsection{Modelo conceitual da pesquisa}

O modelo conceitual que orienta a pesquisa segue as categoriais e variáveis de análise expostas no Quadro 4.

Quadro 4 - Modelo conceitual do estudo

\begin{tabular}{|l|l|}
\hline \multicolumn{1}{|c|}{ Estratégias de Gestão Sustentável } & \multicolumn{1}{c|}{ Desempenho Exportador } \\
\hline Gestão Ambiental & Desempenho Estratégico \\
\hline Responsabilidade Social & Desempenho Econômico \\
\hline Integração da sustentabilidade na estratégia & \\
\hline
\end{tabular}

Fonte: Elaborado pelos autores.

Para análise das estratégias de gestão sustentável, foram utilizados como base os modelos de Placet, Anderson, Fowler (2005) e de Lacy et al. (2010). O desempenho exportador foi analisado a partir dos estudos de Papadopoulos e Martín (2010).

\subsection{Categorias de análise}

No que se refere às estratégias de gestão sustentável, foram analisados aspectos referentes à gestão ambiental, responsabilidade social e integração da sustentabilidade na estratégia empresarial, conforme apresentado no Quadro 5.

Quadro 5 - Categorias e variáveis das estratégias de gestão sustentável

\begin{tabular}{|c|c|c|}
\hline Gestão Ambiental: & Responsabilidade social: & $\begin{array}{l}\text { Integração da sustentabilidade na } \\
\text { estratégia empresarial: }\end{array}$ \\
\hline \multirow{2}{*}{$\begin{array}{l}\text { - Controle de dióxido } \\
\text { de carbono }\end{array}$} & \multirow{2}{*}{$\begin{array}{l}\text { Promoção do bem estar } \\
\text { dos colaboradores }\end{array}$} & - $\quad$ Envolvimento dos stakeholders \\
\hline & & - Importância da sustentabilidade \\
\hline \multirow[t]{2}{*}{$\begin{array}{l}\text { Ecoeficiência nos } \\
\text { processos produtivos }\end{array}$} & \multirow[t]{2}{*}{$\begin{array}{l}\text { - } \begin{array}{l}\text { Promoção do bem estar da } \\
\text { comunidade }\end{array}\end{array}$} & $\begin{array}{ll}\text { - } & \text { Barreiras na implantação da } \\
\text { sustentabilidade }\end{array}$ \\
\hline & & $\begin{array}{ll}\text { - } & \begin{array}{l}\text { Educação interna voltada para } \\
\text { sustentabilidade }\end{array} \\
\end{array}$ \\
\hline \multirow{3}{*}{$\begin{array}{l}\text { - Inovação sustentável e } \\
\text { certificações }\end{array}$} & \multirow{3}{*}{$\begin{array}{l}\text { Promoção do } \\
\text { desenvolvimento } \\
\text { econômico regional }\end{array}$} & $\begin{array}{l}\text { - Diretrizes de sustentabilidade na } \\
\text { estratégia da empresa }\end{array}$ \\
\hline & & - $\quad$ Setor de investimento sustentável \\
\hline & & $\begin{array}{ll}\text { - } & \text { Sustentabilidade no plano de lucros e } \\
& \text { resultados (PLR). } \\
\end{array}$ \\
\hline
\end{tabular}

Fonte: Elaborado a partir de Placet, Anderson, Fowler (2005) e Lacy et al. (2010) 
Com relação ao desempenho exportador foram analisadas características inerentes ao desempenho econômico e estratégico, conforme Quadro 6.

Quadro 6 - Categorias e variáveis do desempenho exportador

\begin{tabular}{|c|c|}
\hline Desempenho estratégico: & Desempenho econômico: \\
\hline - $\quad$ Estratégia para atuação no exterior & $\begin{array}{l}\text { - Evolução do percentual de vendas das } \\
\text { exportações }\end{array}$ \\
\hline - Razões para a entrada no mercado externo & $\begin{array}{l}\text { - Evolução percentual percebida na intensidade } \\
\text { das exportações }\end{array}$ \\
\hline $\begin{array}{l}\text { - Apoio recebido para a entrada no mercado de } \\
\text { exportação }\end{array}$ & $\begin{array}{l}\text { - Evolução percentual percebida na rentabilidade } \\
\text { das exportações }\end{array}$ \\
\hline $\begin{array}{l}\text { - Ações, mecanismos de resposta à pressão dos } \\
\text { competidores }\end{array}$ & $\begin{array}{l}\text { - Evolução percentual percebida na lucratividade } \\
\text { das exportações }\end{array}$ \\
\hline $\begin{array}{l}\text { - Impactos no market share da empresa com as } \\
\text { exportações }\end{array}$ & - Crescimento no número de países atendidos \\
\hline $\begin{array}{l}\text { - Melhorias trazidas a partir de expansão em } \\
\text { mercados estrangeiros }\end{array}$ & $\begin{array}{l}\text { - Percepção dos gestores quanto à participação } \\
\text { do mercado internacional }\end{array}$ \\
\hline $\begin{array}{l}\text { - Obtenção da diversificação de clientes, } \\
\text { Modificação no portfólio de produtos em função } \\
\text { da inserção internacional }\end{array}$ & \multirow[t]{2}{*}{$\begin{array}{l}\text { - Identificação dos indicadores de desempenho } \\
\text { exportador }\end{array}$} \\
\hline $\begin{array}{l}\text { - Grau de realização dos objetivos almejados pela } \\
\text { atividade internacional }\end{array}$ & \\
\hline
\end{tabular}

Fonte: Elaborado a partir de Papadopoulos e Martín (2010).

A partir das categorias de análise apresentadas, procura-se entender a relação entre a adoção de estratégias de gestão sustentáveis e o desempenho exportador de uma empresa da terceira geração da cadeia petroquímica. Estudos anteriores (ROCHA et al, 2013; PALMA et al, 2014) já utilizaram os estudos de Placet, Anderson, Fowler (2005), Lacy et al. (2010) e Papadopoulos e Martín (2010), como modelo para este tipo de estudo.

\subsection{Procedimentos para coleta e análise dos dados}

A coleta de dados ocorreu no mês de agosto de 2016, a partir do envio de um questionário via e-mail. Os dados foram coletados por meio de entrevista semiestruturada com o analista de qualidade e o gerente administrativo da empresa. Para Teixeira (2003) as técnicas como entrevistas, questionários, formulários podem ser usadas para coleta de dados na pesquisa qualitativa.

Para análise dos dados, foi utilizado o método de análise de conteúdo que, de acordo Moraes (1999) é uma técnica para leitura e interpretação do conteúdo de materiais oriundo de comunicação verbal ou não verbal. Segundo Gil (1999) a análise objetiva organizar os dados a fim de possibilitar a construção e fornecimento de respostas ao problema de pesquisa. Já interpretação procura dar um sentido mais amplo às respostas, o que é feito através da sua ligação com os conhecimentos obtidos anteriormente.

\section{Apresentação e discussão dos resultados}

A apresentação dos resultados está organizada em três categorias de análise: i) caracterização da empresa e do respondente; ii) estratégias de gestão sustentável e; iii) desempenho exportador.

\subsection{Perfil da empresa e do entrevistado}


É possível observar através do Quadro 7 as principais características da empresa, do respondente e de sua experiência internacional.

Quadro 7 - Características gerais da empresa
\begin{tabular}{|l|l|}
\hline \multicolumn{2}{|c|}{ Perfil do respondente } \\
\hline Cargo: Caracterização da empresa \\
\hline Tempo de atuação na empresa: & Analista da qualidade/Gerente Administrativo Financeiro \\
\hline Tempo de atuação no setor: & 3 anos/11anos \\
\hline Formação: & 3 anos/18anos \\
\hline \multicolumn{2}{|c|}{ Administrac̃a/Economia } \\
\hline Tempo de existência da empresa (anos): & Indústria e Comércio \\
\hline Qual o ramo de atuação da empresa: & De R\$ 90 milhões até R\$ 300 milhões (média-grande) \\
\hline Receita operacional bruta (em reais) em 2015: & 250 \\
\hline Número total de funcionários: & Aproximadamente 5 anos \\
\hline \multicolumn{2}{|c|}{ Experiência internacional } \\
\hline Tempo de atuação no exterior: & $\begin{array}{l}\text { Antenas parabólicas, reservatórios e tratamento de } \\
\text { fluentes }\end{array}$ \\
\hline Produtos exportados pela empresa: & Foram pouco relevantes \\
\hline $\begin{array}{l}\text { Principais fatos que marcaram a trajetória de } \\
\text { internacionalização da empresa: }\end{array}$ & Paraguai, Bolívia, Uruguai \\
\hline Países para os quais a empresa exporta: & Nenhum \\
\hline Colaboradores no exterior: & Inglês e espanhol \\
\hline $\begin{array}{l}\text { Línguas mais utilizadas nas transações } \\
\text { internacionais da empresa: }\end{array}$ \\
\hline
\end{tabular}

Fonte: Dados da pesquisa.

A empresa, fundada em 1987, localiza-se na região do Médio Alto Uruguai do Rio Grande do Sul. Possui uma trajetória de quase três décadas no mercado de transformação de fibras de vidro (fiberglass) e polietileno e atualmente produz antenas parabólicas, reservatórios de água e tratamento de fluentes. Possui aproximadamente 250 colaboradores em suas três unidades, que estão nos estados do Rio Grande do Sul, Mato Grosso do Sul e Ceará. A empresa exporta seus produtos para países como Paraguai, Bolívia e Uruguai.

\subsection{Estratégias de gestão sustentável}

Com base na entrevista realizada com o analista de qualidade e com o gerente administrativo da empresa, foi possível verificar as ações desenvolvidas pela empresa no que diz respeito a uma gestão para sustentabilidade. Os resultados referentes às estratégias de gestão sustentável foram analisados com base nos estudos de Placet, Anderson e Fowler (2005) e de Lacy et al (2010), expostos a seguir nas seguintes categorias: i) gestão ambiental, ii) responsabilidade social e iii) integração da sustentabilidade na estratégia da empresa.

\subsubsection{Gestão ambiental}

As principais práticas da gestão ambiental estão relacionadas ao controle do dióxido de carbono, a ecoeficiência nos processos produtivos, a redução do consumo de energia, e ao reaproveitamento de resíduos. A empresa utiliza basicamente ar comprimido e energia elétrica para os equipamentos utilizados nos setores de produção. Faz ainda uso de um gerador movido a óleo diesel no horário de pico de consumo de energia, o qual ocorre das $18 \mathrm{~h} 00 \mathrm{~min}$ às 21h00min, emitindo dióxido de carbono (CO2) dentro dos parâmetros aceitáveis. Outra fonte utilizada é o Gás Liquefeito de Petróleo (GLP) no setor de produção de produtos em polietileno. O GLP tem um poder calorífico muito maior do que outros gases e do que a lenha, o consumo de $1 \mathrm{~kg}$ de GLP corresponde o equivalente a 4,5kg de lenha, por exemplo. 
A empresa possui uma política de redução de consumo de energia elétrica, através de formas construtivas isolantes termicamente e iluminação natural através de telhas translucidas. A empresa ainda busca a reutilização e a reciclagem dos resíduos gerados e toda a perda na produção de peças em polietileno é reciclada e transformada em produtos de uso menos nobre. Parte do resíduo da produção dos produtos em fibra de vidro é transformada em subprodutos, como, por exemplo, tachões de sinalização rodoviária. Ainda é feita a captação e uso de água da chuva a fim de evitar o uso da água tratada no setor industrial.

Ao analisar as práticas de gestão ambiental, é possível identificar que a empresa é proativa já que possui práticas e processos internos sustentáveis que vão além das normas legais. As práticas de gestão ambiental demonstram que a empresa está de acordo com os critérios do desenvolvimento sustentável para as organizações e stakeholders de Placet, Anderson e Fowler (2005).

\subsubsection{Responsabilidade social}

As principais práticas da responsabilidade social estão relacionadas ao cuidado com a saúde dos colaboradores, com o bem estar da comunidade e com a promoção do desenvolvimento regional. A empresa possui plano de saúde sem nenhum custo para os colaboradores, reuniões mensais da Comissão Interna de Prevenção de Acidentes (CIPA) com participação ativa dos colaboradores nas ideias, decisões e ações. Participa de programas sociais de reciclagem, apoia entidades beneficentes e realiza projetos comunitários por meio de doações e com a participação da equipe de colaboradores.

Para a promoção do desenvolvimento regional a empresa possui incentivos educacionais e parcerias com universidades. Participa do programa de Jovem Aprendiz (possui entre 10 e 20 jovens permanentemente), promove treinamentos e palestras locais e nacionais que incluem temas sobre conscientização ambiental e empreendedorismo. Recebe alunos e instituições em suas unidades promovendo a integração comunitária e extensão educacional. Tem parceria com instituições de ensino para estágios curriculares e trabalhos de curso de graduação e pósgraduação.

A análise das práticas de responsabilidade social da empresa demonstra estar de acordo com os estudos de Placet, Anderson e Fowler (2005) os quais sugerem que o desenvolvimento sustentável no contexto das organizações e seus stakeholders possui a responsabilidade social como um de seus objetivos.

\subsubsection{Integração da sustentabilidade na estratégia empresarial}

As principais evidências da integração da sustentabilidade na estratégia empresarial estão relacionadas ao envolvimento dos stakeholders no desenvolvimento de estratégias sustentáveis, na sensibilização e importância da sustentabilidade para os funcionários e alta direção, na inovação tecnológica sustentável, no setor de reaproveitamento de matéria prima, no plano de lucros e resultados (PLR), e nas regulamentações ou certificações voltadas para sustentabilidade.

A empresa é gerenciada pelos sócios-proprietários e dispõe de profissionais nas diversas áreas para exercerem a gestão, busca relações duradouras com fornecedores e outros envolvidos. Tem conhecimento amplo das políticas legais que envolvem o negócio e busca a sustentabilidade dele através do atendimento destas demandas. Procura desenvolver materiais e processos que sejam ambientalmente mais eficazes, os próprios produtos fornecidos pela empresa têm grande enfoque sustentável, uma vez utilizados estão colaborando para o meio ambiente. A empresa ainda utiliza materiais ecologicamente corretos na fabricação de seus produtos e também realiza o reprocessamento de materiais realizando inovações sustentáveis. 
A empresa possui um setor exclusivamente ligado para o reaproveitamento da matériaprima perdida, tornando a mesma em novos produtos para uso interno ou comercialização. Toda a matéria-prima perdida (chão, rebarbas, varredura, plásticos, etc.) é direcionada para o setor de reprocessamento onde será selecionada e reaproveitada, integrando assim, aspectos sustentáveis no plano de lucros e resultados.

Palestras e treinamentos fazem parte da rotina da empresa, o que contribui para a conscientização social e ambiental nas comunidades. Esses treinamentos e palestras envolvem lojistas, a equipe, profissionais da construção civil e gestores públicos. Quanto às regulamentações e certificações voltadas para a sustentabilidade a empresa menciona os alvarás de funcionamento, licenças de operação, licença ambiental e os certificados da Associação Brasileira de Normas Técnicas (ABNT) para seus produtos.

A análise da integração da sustentabilidade na estratégia empresarial permite identificar que a empresa segue o critério de que a sustentabilidade deve estar totalmente integrada às operações e às estratégias de uma empresa não sendo vista de forma individual, como sugerido por Lacy et al (2010).

\subsection{Desempenho exportador}

Para identificar as práticas relacionadas ao desempenho exportador da empresa, foi utilizado um modelo adaptado dos estudos de Papadopoulos e Martín (2010), cujos resultados são categorizados a partir do desempenho estratégico e o desempenho econômico.

Quanto ao desempenho estratégico, verificou-se que a principal estratégia utilizada pela empresa nos mercados internacionais é a exportação por meio de intermediários no Brasil. Os impactos no market share da empresa com as exportações não foram relevantes. As melhorias trazidas a partir da expansão em mercados estrangeiros foram à qualidade e a diversificação de clientes. Não houve modificação de portfólio de produtos em função da inserção internacional. A empresa avalia que o grau de realização dos gestores em relação aos objetivos estratégicos provenientes da atividade internacional não foi significante.

Já no desempenho econômico, foi identificado uma queda do percentual de vendas das exportações; a intensidade de exportações, rentabilidade e crescimento ao número de países foi insignificante. A participação da empresa no mercado internacional não é relevante; e esta não utiliza indicadores para avaliar seu desempenho exportador.

A análise destes fatores permite identificar que a entrada no mercado internacional usando intermediários no Brasil segue a lógica de Johanson e Vahlne (1990) ao indicar que a principal forma de entrada no mercado internacional deve ser a que envolve um menor risco na internacionalização de produtos e serviços. Embora a empresa não tenha alterado seu portfólio em função da inserção internacional, o processo trouxe melhoria na qualidade dos produtos, o que está de acordo com Arbix, Salermo e De Negri (2005) que em seus estudos constatam que a exposição das firmas brasileiras aos consumidores mais exigentes força mudanças nos produtos exportados em direção a maior qualidade e diferenciação.

Os estudos de Papadopoulos e Martín (2010) que amparam a avaliação do desempenho exportador a partir das dimensões econômica e estratégica permitem avaliar que a empresa estudada tanto na dimensão econômica quanto estratégica possui um baixo desempenho.

\section{Considerações finais}

Este trabalho teve por objetivo identificar as estratégias de gestão sustentável e o desempenho exportador de uma empresa da terceira geração da cadeia petroquímica. As práticas de gestão ambiental caracterizam que empresa possui práticas e processos internos sustentáveis que vão além das normas legais, o que está de acordo com as ideias de Bansal e 
Roth, (2000) e Yang et al, (2010). As práticas de responsabilidade social permitem identificar que empresa se preocupa com a qualificação da mão de obra local, é aberta a estudos e pesquisas juntos às universidades e instituições de ensino. Insere o jovem no mercado de trabalho e busca a criação de valor para a sociedade e para seus colaboradores. Ambas estão de acordo com os critérios do desenvolvimento sustentável para as organizações e seus stakeholders de Placet, Anderson e Fowler (2005).

A sustentabilidade se integra na estratégia empresarial de diversas formas, seja através da atuação na comunidade ou com reaproveitamento de matéria-prima, materiais ecologicamente corretos e por estar integrada no plano de lucros e resultados. A análise da integração da sustentabilidade na estratégia empresarial permite o entendimento de que a empresa está de acordo com o critério de Lacy et al o qual sugere que a sustentabilidade deve estar totalmente integrada às operações e às estratégias de uma empresa não devendo ser vista de forma individual.

Para a análise do desempenho exportador, à luz do modelo de Papadopoulos e Martín (2010), pode-se evidenciar que a empresa entrou no mercado estrangeiro por meio de intermediários no Brasil e não sofreu grandes modificações em função da inserção internacional. No que se refere ao desempenho econômico, destaca-se que o resultado do processo de internacionalização foi insignificante para a empresa e que esta não avalia tal perspectiva com nenhum indicador. Em suma, pode-se constatar que a empresa estudada tanto na dimensão econômica quanto estratégica possui um baixo desempenho.

Adicionalmente este trabalho possui algumas limitações decorrentes da incipiência de trabalhos relacionados. Por se tratar de um tema relevante para o contexto brasileiro, sugere-se um aprofundamento do tema em pesquisas futuras. Possíveis extensões poderiam incluir amostras em outros níveis da cadeia petroquímica bem como outras abordagens metodológicas.

\section{Referências}

ABIPLAST. Perfil 2014 da Indústria Brasileira de Transformação de Material Plástico Associação Brasileira da Indústria do Plástico. Disponível em:

http://file.abiplast.org.br/download/links/2015/perfil_abiplast_2014_web.pdf. Acesso em: 30 de maio de 2016.

ALIGLERI, L.; ALIGLERI, L. A.; KRUGLIANSKAS, I. Gestão socioambiental: responsabilidade e sustentabilidade do negócio. São Paulo: Atlas, 2009.

ALIEVI, R. M.; ANTINARELLI, A. Construindo a Gestão Estratégica Sustentável: um estudo sobre a empresa Mercur S.A. Revista de Administração da UFSM, v. 8, n. Ed. Especial, p. 69-83, 2015. DOI: http://dx.doi.org/10.5902/1983465916352.

ARBIX, G.; SALERNO, M. S.; DE NEGRI, J. A. Internacionalização gera emprego de qualidade e melhora a competitividade das firmas brasileiras. In: DE NEGRI, J. A. (Coord.). Inovações, padrões tecnológicos e desempenho das firmas industriais brasileiras. [S. 1.]: Instituto de Pesquisa Econômica Aplicada - IPEA, 2005.

BANSAL, P.; ROTH, K. Why Companies Go Green: A Model of Ecological Responsiveness. Academy of Management Journal, v. 43, n.4, p. 717-736, 2000. DOI: http://dx.doi.org/10.2307/1556363. 
CARDOSO, A. C. F. O programa estratégico integrado de gestão para o desenvolvimento sustentável. 289f. Tese - (Doutorado em Administração) Faculdade de Economia, Administração e Contabilidade da Universidade de São Paulo, São Paulo, 2012.

CAVUSGIL, S. T.; ZOU S. Marketing strategy-performance relationship: an investigation of the empirical link in export market ventures. Journal of Marketing. v. 58, p. 1-21, 1994.

CIASULLO, M. V.; TROISI, O. Sustainable value creation in SMEs: A case study. TQM Journal, 2013, v. 25, n. 1, p. 44-61. DOI: http://dx.doi.org/10.1108/17542731311286423.

DIAS,V. V.; SCHUSTER, M. S.; DIAS, R. R. Orientação Da Gestão Sustentável De Uma Empresa Química Com Atividade Internacional. Internext (São Paulo), v. 8, p. 68-87, 2013. DOI: http://dx.doi.org/10.18568/1980-4865.8168-87.

DUNNING, J. H. The globalization of business the challenge of the 1990s. New York: Routledge, 1993.

ELKINGTON, J. Cannibals With Forks: the Triple Bottom Line of 21st Century Business. Capstone: Oxford, 1997.

FIALHO, F. A. P.; MACEDO, M.; MITIDIERI, T. C.; MONTIBELLER, G. Gestão da sustentabilidade na era do conhecimento: o desenvolvimento sustentável e a nova realidade da sociedade pós-industrial. Florianópolis: Visual Books, 2008.

FIALHO, F. A. P.; MACEDO, M.; MITIDIERI, T. C.; MONTIBELlER, G. Empreendedorismo na era do conhecimento. Florianópolis: Visual Books, 2006.

GIL, A .C. Métodos e técnicas de pesquisa social. 5.ed. São Paulo: Atlas, 1999.

GOMES, G.; DVORSAK, P.; HEIL, T. Indústria Petroquímica no Brasil: Situação Atual e Perspectivas. (2005). Disponível em: http://www.bndespar.gov.br/SiteBNDES/export/sites/default/bndes pt/Galerias/Arquivos/con hecimento/bnset/set2105.pdf> Acesso em: 30 de setembro de 2006.

GONZÁLES-BENITO, J.; GONZÁLES-BENITO, O. Environment proactivity and business performance: na empirical analysis. The International Journal os Management Science. v. 33, n. 1. p. 01-15, 2005.

GONZÁLES-BENITO, J.; GONZÁLES-BENITO, O. A review of determinant factors of environment proactivity. Business Strategy and the Environment. v. 15, p. 87-102, 2006. DOI: http://dx.doi.org/10.1002/bse.450.

HIDALGO, A. B.; DA MARA, D. Produtividade e desempenho exportador das firmas na Indústria de Transformação Brasileira. Estudos Econômicos (São Paulo), vol.39 n. 4 São Paulo, 2009. DOI: http://dx.doi.org/10.1590/S0101-41612009000400001.

JOHANSON, J.; WIEDERSHEIM -PAUL, P.F. The Internationalization of the firm. Four Swedish Cases. Journal of Management Studies, [S. 1.], p. 305-322, Oct. 1975. 
JOHANSON, J; VAHLNE, J. E. The Mechanism of Internationalization. International Marketing Review, [S. 1.], v. 7, n. 4, p. 11-24, 1990.

JOHANSON, J.; VAHLNE, J. E. The internationalization process of the firm: a model of knowledge development and increasing foreign market commitments. Journal of International Business Studies, v. 8, n. 1, p. 23-32, 1977.

KLOTZLE, M. C.; THOMÉ, C. C. Fatores associados ao desempenho exportador de micros, pequenas e médias empresas brasileiras. Revista de Administração, v. 41, n. 3, p. 339-346, 2006.

LACY, P.; COOPER, T.; HAYWARD, R.; NEUBERGER, L. A new era of sustainability: CEO reflections on progress to date, challenges ahead and the impact of the journey toward a sustainable economy. [S. 1.]: UN Global Compact - Accenture Sustainability Services, 2010.

MASCARENHAS, M, P, V.; COSTA, C, A. F. Responsabilidade Social e Ambiental das Empresas. Uma perspectiva sociológica. Latitude, vol. 7, n 2, p.141-167, 2011.

MERRIAM, S. B. Qualitative research and case study applications in education. São Francisco (CA): Jossey-Bass, 1998.

MORAES, R. Análise de conteúdo. Revista Educação, [S. 1.], v. 22, n. 37, p.7-32, Porto Alegre, 1999.

MOTA, J. C. V. Condicionante da internacionalização e desempenho exportador: evidências no setor sucroalcooleiro brasileiro. 125f. Dissertação - (Mestrado em Administração) Universidade Federal da Paraíba, João Pessoa, 2012.

PALMA, E. P., GOMES, C. M., KNEIPP, J. M.; BARBIERI DA ROSA, L. A. Sustainable Strategies and Export Performance: an analysis of companies in the gems and jewelry industry. RBGN-Revista Brasileira de Gestão de Negócios, v 16, p. 25-42, 2014.

PAPADOPOULOS, N.; MARTÍN, O. M. Toward a model of the relationship between internationalization and export performance. International Business Review, [S. 1.], v. 19, p. 388-406, 2010. DOI: http://dx.doi.org/10.1016/j.ibusrev.2010.02.003.

PASQUALOTTO, C.; UGALDE, M. M. Adaptações de produto no processo de internacionalização de empresas gaúchas do setor moveleiro. Internext - Revista Eletrônica de Negócios Internacionais da ESPM, São Paulo, v. 5, n. 2, p. 46-65, jul./dez. 2010.

PLACET, M.; ANDERSON, R.; FOWLER, K. M. Strategies for Sustainability. Research Tecnology Management, [S. 1.], v. 48, n. 5, p. 32-41, 2005.

ROCHA, A. C.; CAMARGO, C. R.; KNEIPP, J. M.; ÁVILA, L. V.; GOMES, C. M.; MADRUGA, L. R. R. G. Estratégias sustentáveis e desempenho exportador no setor moveleiro paranaense. Revista de Administração FACES Journal, v. 12, n. 3, p. 9-27, 2013. DOI: http://dx.doi.org/10.21714/1984-6975FACES2013V12N3ART1178. 
setoriais. 2008. Disponível em: http://189.39.124.147:8030/downloads/plastico.pdf. Acesso em 02 de maio de 2016.

TEIXEIRA, E. B.A análise de dados na pesquisa científica: importância e desafios em estudos organizacionais. Desenvolvimento em Questão, v. 1, n. 2, p. 177-201, 2003. DOI: http://dx.doi.org/10.21527/2237-6453.2003.2.177-201.

VIOLA, E. As complexas negociações internacionais para atenuar as mudanças climáticas. In: TRIGUEIRO, A. (Ed.). Meio Ambiente no século 21: 21 especialistas flamam da questão ambiental nas suas áreas de conhecimento. Rio de Janeiro: Sextante, 2003.

YANG, C.; LIN, S.; CHAN, Y.; SHEU, C. Mediated effect of environmental management on manufacturing competitiveness: An empirical study. International Journal of Production Economics. V. 123, Issue 1, January 2010, Pages 210-220, 2010. DOI: http://dx.doi.org/10.1016/j.ijpe.2009.08.017.

WRIGHT, J. T. C.; GIOVINAZZO, R. A. A política industrial e a estratégia da nação. In: FLEURY, M. T.; FLEURY, A. (Orgs.). Política Industrial. São Paulo. Publifolha, 2004. 